\title{
Representasi Pendidikan dalam Novel “Negeri 5 Menara” Karya Ahmad Fuadi dan Novel "Sang Pemimpi" Karya Andrea Hirata
}

\author{
Tantrie Leonita \\ Program Studi Magister Ilmu Linguistik FIB Universitas Jember \\ leonytha37@gmail.com
}

\begin{abstract}
This research focused on (1) descriptive stylistic, (2) genetic stylistic, and (3) representation of education on Negeri 5 Menara written by Ahmad Fuadi the choice of words included greetings, regional language lexicons (Minang, Javanese, Sundanese), and foreign language lexicons (Arabic, English, French). While in the Sang Pemimpi novel written by Andrea Hirata, the choices of words included the lexicon area (Malay, Belitung), foreign language lexicon (English), and scientific word. The style of language found in Negeri 5 Menara novel written by Ahmad Fuadi and Sang Pemimpi novel written by Andrea Hirata was focused on five styles of language, namely, personification, metaphor, simile, hyperbola, and metonymic. In the Negeri 5 Menara novel written by Ahmad Fuadi and Sang Pemimpi novel written by Andrea Hirata there was phenomenon revealed in an implicit word meaning using the theory of representation of Islamic boarding schools in Fuadi's N5M novel and public school in Andrea's SP novel. The two novels were studied using descriptive and genetic stylistic approaches.
\end{abstract}

Keywords: Islamic boarding school, public schools, stylistics, novels.

\begin{abstract}
ABSTRAK
Penelitian ini memfokuskan permasalahan pada (1) stilistika deskriptif, (2) stilistika genetis, dan (3) representasi pendidikan. Pada novel Negeri 5 Menara karya Ahmad Fuadi pilihan kata meliputi kata sapaan, leksikon bahasa daerah (bahasa Minang, Jawa, Sunda), leksikon bahasa asing (bahasa Arab, Inggris, Prancis). Pada novel Sang Pemimpi karya Andrea Hirata pilihan kata meliputi kata leksikon bahasa daerah (Melayu dan Belitung), leksikon bahasa asing (Inggris), dan kata ilmiah. Gaya bahasa yang terdapat pada kedua novel difokuskan pada lima gaya bahasa yaitu; majas personifikasi, majas metafora, majas simile, majas hiperbola, dan majas metonimia. Pada novel Negeri 5 Menara karya Ahmad Fuadi dan novel Sang Pemimpi karya Andrea Hirata terdapatnya fenomena yang terkuak dalam sebuah makna kata yang tersirat dengan menggunakan pengembangan teori representasi pendidikan pondok pesantren pada novel N5M karya Fuadi dan sekolah umum pada novel SP karya Andrea. Kedua novel tersebut dikaji dengan pendekatan stilistika deskriptif dan genetik.
\end{abstract}

Kata kunci: pondok pesantren, sekolah umum, stilistika, novel. 


\section{A. PENDAHULUAN}

Salah satu novel yang memiliki nilai pendidikan tinggi dan mengedepankan nilai-nilai pembelajaran dalam kehidupan adalah novel Negeri 5 Menara karya Ahmad Fuadi dan novel Sang Pemimpi karya Andrea Hirata. Novel-novel tersebut sangat popular di masyarakat Indonesia, kedua novel tersebut pernah menjadi best seller dan diangkat sebagai karya film Indonesia. Novel Negeri 5 Menara dan Sang Pemimpi memberi pembelajaran yang sangat penting bagi masyarakat, khususnya para remaja. Banyak pelajaran yang dapat dipetik dari kedua novel tersebut. Novel Negeri 5 Menara dan Sang Pemimpi merupakan novel yang sangat menarik untuk diteliti, karena novel ini mengandung nilai pendidikan dan memperluas wacana kita dalam sektor pendidikan. Selain itu juga terdapatnya banyak penggunaan gaya bahasa yang dominan pada masing-masing pendeskripsian kedua novel tersebut, sehingga semakin membuat novel memiliki nilai lebih.

Pada novel Negeri 5 Menara diungkap problematika pendidikan sekaligus mendeskripsikan segala bentuk aktivitas dan rutinitas sehari-hari para santri dengan ustaz (guru) untuk memperdalam ilmu agama dan pengetahuan umum. Kemandirian dan kedisiplinan yang diterapkan dalam proses pembelajaran santri di pondok pesantren Madani mampu membentuk kepribadian yang kuat dan memiliki akhlaqul kharimah dalam pribadi masingmasing santri.

Lain halnya dengan novel Sang Pemimpi karya Andrea Hirata yang sama- sama mengangkat tema pendidikan, kehidupan sehari-hari di sekitar penulis, mulai dari perjuangan menghadapi kerasnya kehidupan agar mendapatkan pendidikan yang layak, semangat dan usahanya menempuh pendidikan hingga meraih cita-cita meski dengan keterbatasan ekonomi. Sebuah perjuangan dalam dunia pendidikan dengan menimba ilmu sambil bekerja dikarenakan kondisi ekonomi yang tidak menunjang, dan kegigihan dalam menjalani hidup dikisahkan dengan bahasa yang memikat dalam novelnya yang berjudul Sang Pemimpi. Pada novel Sang Pemimpi juga dideskripsikan gambaran umum pola penerapan sistem pendidikan sekolah formal antara siswa dengan guru dan memiliki perbedaan dalam pola penerapan sistem pendidikan di pondok pesantren yang terdapat pada novel Negeri 5 Menara. Pendidikan pondok pesantren dan pendidikan sekolah umum pada kedua novel ini juga membawa pengaruh dan mengungkap perbedaan kepribadian dari masingmasing tokoh. Sebaliknya pada kedua novel penelitian ini terdapatnya kesamaan yang dapat dideskripsikan yaitu semangat yang tinggi dalam menempuh pendidikan meskipun banyak rintangan dan hambatan, namun tidak dapat memupus tokoh untuk meraih mimpi-mimpi mereka.

Novel Negeri 5 Menara dan Sang Pemimpi ini juga sekaligus memotivasi pembaca bahwa semua orang berhak bermimpi dan memiliki impian. Orang miskin sekali pun harus tetap bermimpi. Impian itu akan dapat terwujud tergantung dari niat dan usaha masing- 
masing individu itu sendiri. Pada novel Negeri 5 Menara, diungkap latar pendidikan di pondok pesantren yang mulai pagi hingga malam merupakan proses pembelajaran ${ }^{1}$, berbeda dengan novel Sang Pemimpi mengungkapkan latar pendidikan formal (umum) yaitu SMU2. Pada sekolah formal lebih diutamakan pembelajaran ilmu pengetahuan umum dibandingkan ilmu agama, waktu efektif pembelajaran di sekolah umum pada umumnya berlangsung sekitar delapan jam.

Setiap pengarang dalam membuat karya akan memperlihatkan penggunaan bahasa dengan ciri dan pola masingmasing yang membedakan dengan pengarang lainnya. Penggunaan bahasa yang khas dalam karyanya tentu akan memperlihatkan ciri-ciri individualisme, originalitas, dan gaya masing-masing pengarang. Keanekaragaman dan style Ahmad Fuadi melalui novel Negeri 5 Menara dan Andrea Hirata melalui novel Sang Pemimpi, sangat perlu dan menarik untuk diteliti.

Masing-masing pengarang akan menggunakan dan memperlihatkan gayanya yang khas dalam penggunaan bahasa. Pola-pola dan ciri-ciri kebahasaan yang digunakan pengarang akan menjadi pembeda pengarang yang satu dengan lainnya. Penggunaan bahasa dengan polapola dan ciri-ciri yang khas juga akan menunjukkan keaslian (originalitas) pikiran-pikiran pengarang terhadap sebuah persoalan termasuk persoalan pendidikan. Salah satu kekhasan penggunaan bahasa tersebut diperlihatkan oleh Ahmad Fuadi melalui novel Negeri 5 Menara (selanjutnya akan disingkat N5M) dan Andrea Hirata melalui novel Sang Pemimpi (SP). Kekhasan dalam novel $N 5 M$ tampak pada pemanfaatan pilihan kata yang khas, seperti leksikon bahasa daerah, leksikon asing, dan majas sedangkan kekhasan dalam novel $S P$ tampak pada leksikon bahasa daerah, leksikon asing dan kata yang berhubungan dengan ilmiah. Novel N5M dan SP menarik untuk dikaji secara stilistika karena kedua novel tersebut mengandung banyak keanekaragaman gaya bahasa dan samasama mengangkat persoalan pendidikan, baik pendidikan pesantren dan pendidikan di sekolah umum. Latar belakang Ahmad Fuadi sebagai tokoh yang mengalami langsung menempuh pendidikan di dalam pesantren berkontribusi banyak terhadap lahirnya novel dengan kekhasan bahasa tersendiri. Selain itu dengan latar belakang seorang wartawan membuat novel Fuadi tampak dideskripsikan dengan baik dan nyata. Begitu juga Andrea Hirata yang berasal dari latar belakang penduduk setempat (Belitung) seolah-olah mewakili keironian yang dialami tokoh-tokoh tersebut dalam mengenyam pendidikan.

Gambaran-gambaran di atas membuat peneliti untuk mengungkap stilistika novel N5M karya Ahmad Fuadi dan SP karya Andrea Hirata. Kajian stilistika ini diharapkan akan terungkap gaya-gaya kepengarangan yang digunakan oleh kedua pengarang lewat karyanya masing-masing. Selain itu, peneliti juga akan mengungkap tentang representasi

\footnotetext{
${ }^{2}$ Andrea, Sang Pemimpi.

\footnotetext{
${ }^{1}$ Fuadi, Negeri 5 Menara.
} 
pendidikan pesantren yang digambarkan oleh Fuadi dalam karyanya N5M dan representasi pendidikan sekolah umum yang digambarkan oleh Andrea dalam SP. Berkaitan dengan latar belakang yang telah peneliti paparkan di atas maka judul dalam penelitian ini adalah "Representasi Pendidikan dalam Novel Negeri 5 Menara Karya Ahmad Fuadi dan Novel Sang Pemimpi Karya Andrea Hirata: Kajian Stilistika".

Berdasarkan latar belakang di atas, perumusan masalah yang dapat diteliti adalah sebagai berikut.

1. Bagaimanakah penggunaan stilistika deskriptif dalam novel $N 5 M$ karya A.Fuadi dan SP karya Andrea Hirata?

2. Bagaimanakah stilistika genetis dalam N5M karya A.Fuadi dan SP karya Andrea Hirata?

3. Bagaimanakah representasi pendidikan pesantren dalam novel N5M karya A.Fuadi dan pendidikan umum dalam novel SP karya Andrea Hirata?

Berdasarkan jenisnya, penelitian ini adalah penelitian deskriptif kualitatif dengan pendekatan teori stilistika baik deskriptif maupun genetik. Menurut Bungin (2014:68), penelitian dengan format deskriptif kualitatif bertujuan untuk menggambarkan, meringkaskan berbagai kondisi, berbagai situasi, atau berbagai fenomena realitas sosial yang ada di masyarakat atau objek penelitian. ${ }^{3}$ Teknik pengumpulan data dalam penelitian ini adalah teknik pustaka, simak dan catat. Teknik ini dilakukan dengan

\footnotetext{
${ }^{3}$ Bungin, Penelitian Kualitatif, 68.
}

cara membaca, mencatat dan mengumpulkan data-data dari sumber data-data tertulis. Selanjutnya, data-data yang terkumpul diperikan sesuai kebutuhan analisis. Kemudian, langkah selanjutnya peneliti mengklasifikasi dan memverifikasi data sesuai dengan kategori data deskriptif dan genetik, kemudian data deskriptif diklasifikasi lagi sesuai kategori diksi dan majas, sedangkan data genetik diklasifikasi berdasarkan kategori representasi pendidikan di lingkungan sekolah pondok pesantren dan lingkungan sekolah umum. Hal ini dimaksudkan agar peneliti mendapatkan dan mengetahui wujud data yang akan digunakan untuk menjawab pertanyaan penelitian.

\section{B. PEMBAHASAN}

Stile (gaya bahasa) menurut Ratna, adalah cara-cara penggunaan medium bahasa secara khas, sehingga tujuan dapat tercapai secara maksimal. ${ }^{4}$ Gaya bahasa mencakup keseluruhan cara yang digunakan pengarang, meliputi gaya dan majas. Gaya bahasa yang dimaksud Ratna adalah berkaitan dengan masalah umum penulisan, penyajian, komposisi, struktur penceritaan, penampilan karakter huruf, cover, dan ukuran buku atau karangan, sedangkan majas (figures of speech), adalah pilihan kata tertentu yang digunakan penulis atau pembicara untuk tujuan memperoleh aspek keindahan. Berdasarkan pembahasan penelitian, sesuai dengan permasalahan pada penelitian kajian stilistika dalam novel N5M karya Ahmad Fuadi dan SP karya

\footnotetext{
${ }^{4}$ Ratna, Stilistika Kajian Puitika Sastra, Dan Budaya, 166.
} 
Andrea Hirata dapat disimpulkan bahwa, secara umum unsur yang ada di dalam novel ada dua, yaitu gaya kata dan gaya kalimat, namun dalam penelitian ini hanya akan dideskripsikan gaya kata yang meliputi diksi dan majas.

1. Diksi dan Majas yang terdapat dalam Novel N5M Karya Ahmad Fuadi

Keunikan dan pilihan kata yang terdapat dalam novel N5M karya Fuadi sebagai berikut:

a. Pilihan kata dan leksikon kata sapaan Bahasa Minang yang terdapat pada novel N5M antara lain; kata 'amak', 'buyuang', 'waang', 'ambo'.

b. Pilihan kata dan leksikon Bahasa Jawa yang terdapat pada novel N5M diantaranya: 'kuping', jabang bayi'.

c. Pilihan kata dan leksikon Bahasa Sunda yang terdapat pada novel N5M diantaranya: 'Urang Sunda', 'kumaha'.

d. Leksikon Bahasa Asing yang terdapat pada novel $N 5 M$ karya Fuadi ada tiga bahasa antara lain Bahasa Arab, Bahasa Inggris dan Bahasa Prancis. Leksikon bahasa yang paling didominasi dalam tulisan Ahmad Fuadi dalam N5M adalah leksikon Bahasa Arab, terutama yang terkait dengan ilmu fiqih 5, tauhid (ketuhanan), dan akhlak (perilaku).

Pemakaian gaya bahasa yang terdapat di dalam novel N5M karya Fuadi sangat beragam. Pembahasan gaya bahasa dalam penelitian ini difokuskan pada majas personifikasi, metafora, simile, hiperbola dan metonimia. Pemanfaatan

\footnotetext{
${ }^{5}$ Mudawam, “Asy-Syir'ah SYARI’AH-FIQIHHUKUM ISLAM Studi Tentang Konstruksi Pemikiran Kontemporer."

${ }^{6}$ Nurgiyantoro, Stilistika.
}

lima majas tersebut sangat produktif walaupun sebetulnya juga ada pemanfaatan jenis majas yang lain. Berikut beberapa contoh pemanfaatan majas Fuadi di dalam novel N5M.

1) Majas personifikasi menurut Nurgiyantoro, merupakan majas dengan ciri memberikan sifat-sifat kemanusiaan kepada benda mati. Sifat-sifat kemanusiaan yang ditransfer kepada benda atau makhluk bukan manusia tersebut dapat berupa ciri fisik, sifat, karakter, tingkah laku verbal dan nonverbal, pikiran dan berpikir, perasaan dan berperasaan, termasuk juga sikap dan bersikap. $^{6}$ Adapun contoh majas personifikasi tersebut yaitu:
(a) Ketukan-ketukan halus terdengar setiap gumpal salju menyentuh kaca di depanku. ${ }^{7}$
(b) Matahari sore menggantung condong ke barat berbentuk piring putih susu. ${ }^{8}$

2) Majas metafora dibagi menjadi dua jenis menurut Nurgiyantoro, yaitu metafora eksplisit dan metafora implisit. ${ }^{9}$ Metafora eksplisit adalah jenis perbandingan yang menyebutkan secara jelas sesuatu yang dibandingkan dan pembandingnya, sedangkan metafora implisit merupakan jenis perbandingan yang langsung mengemukakan pembandingnya. Sebagaimana yang terdapat pada data berikut.

\footnotetext{
${ }^{7}$ Fuadi, Negeri 5 Menara, 1.

${ }^{8}$ Fuadi, 1.

${ }^{9}$ Nurgiyantoro, Stilistika.
} 
(a) Banyak orang melihat bahwa pondok adalah buat anak yang cacat produksi. Baik karena tidak mampu menembus sekolah umum yang baik, atau karena salah gaul dan salah arus. ${ }^{10}$

(b) "Percayalah kalian bisa kalau berusaha. Sesungguhnya bahasa asing adalah anak kunci jendelajendela dunia." 11

3) Majas simile

Gaya bahasa bentuk simile ditandai dengan kata pembanding "seperti", "laksana", "seumpama", "bagaikan", "selayaknya", dan lain sebagainya. Perbandingan ini merupakan perbandingan yang eksplisit karena langsung menyatakan sesuatu yang memiliki kesamaan atau kemiripan dengan yang lain. Baldick mengemukakan bahwa perbandingan dua hal yang berbeda tersebut bisa berupa benda, fisik, aksi, perbuatan, atau perasaan. ${ }^{12}$ Sebagaimana yang terdapat pada data berikut.

(a) Bagaimana kalau pondok itu seperti penjara? Bagaimana kalau gambaran Pondok Madani dari Pak Etek Gindo itu salah?13

(b) Anak-anakku, ilmu bagai nur, sinar. Dan sinar tidak bisa datang dan ada di tempat yang gelap. Karena itu, bersihkan hati dan kepalamu, supaya sinar itu bisa datang, menyentuh dan menerangi kalbu kalian semua. ${ }^{14}$

\footnotetext{
${ }^{10}$ Fuadi, Negeri 5 Menara, 20.

${ }^{11}$ Fuadi, 51.

${ }^{12}$ Baldick, The Concise Oxford Dictionary of Literary Terms, 237.

${ }^{13}$ Fuadi, Negeri 5 Menara, 17.

${ }^{14}$ Fuadi, 190.
}

4) Majas hiperbola merupakan gaya bahasa yang mengandung pernyataan berlebih-lebihan, dengan membesarbesarkan suatu hal. Keraf mengungkapkan bahwa hiperbola merupakan gaya bahasa yang terkesan membesar-besarkan suatu hal yang diungkapkan secara berlebihan. ${ }^{15}$ Sebagaimana yang terdapat pada data berikut.

(a) Walau dingin mencucuk tulang, hari ini aku lebih bersemangat dari biasa. ${ }^{16}$

(b) Telunjuknya lurus teracung tinggi ke udara, suaranya menggelegar, sorot matanya berkilat-kilat menikam kami satu persatu. ${ }^{17}$

5) Majas metonimia adalah gaya bahasa yang menggunakan kata tertentu sebagai pengganti kata sebenarnya karena dekatnya pertalian. Sebagaimana yang terdapat pada data berikut.

(a) Kata mutiara sederhana tapi kuat. Yang menjadi kompas kehidupan kami kelak. ${ }^{18}$

(b) Saking seringnya kami berkumpul di kaki menara, kawan-kawan lain menggelari kami dengan Sahibul Menara, orang yang punya menara. 19

\section{Diksi dan Majas yang terdapat dalam Novel SP Karya Andrea Hirata}

\footnotetext{
${ }^{15}$ Keraf, Diksi Dan Gaya Bahasa, 135.

${ }^{16}$ Fuadi, Negeri 5 Menara, 2.

${ }^{17}$ Fuadi, 40.

${ }^{18}$ Fuadi, 41.

${ }^{19}$ Fuadi, 94
} 
Keunikan dan pilihan kata yang terdapat dalam novel $S P$ karya Andrea sebagai berikut:

a. Pilihan kata dan leksikon kata sapaan bahasa daerah (Melayu, Belitung) yang terdapat pada novel $S P$ antara lain; Mak Cik, Pak Cik, Boi. Selain itu Andrea memanfaatkan kata panggilan yang berasal dari suku Hakka (dikenal dengan orang Khek) yaitu Ngai, Taikong, Tauke, Capo.

b. Leksikon Bahasa Asing yang terdapat pada novel SP karya Andrea didominasi oleh bahasa Inggris diantaranya yaitu, reign of fire, in charge, excited, civitas academica, job description.

c. Penggunaan kata-kata ilmiah yang juga ikut mendominasi pada novel $S P$ karya Andrea antara lain; momentum, phyrite, radio aktif, fluktuasi.

Pemakaian gaya bahasa yang terdapat dalam novel $S P$ karya Andrea sangat beragam. Sebagai novel yang berlatar belakang kehidupan di pulau Belitung, novel SP karya Andrea juga kaya dengan ungkapan-ungkapan permajasan. Berikut beberapa contoh pemanfaatan majas oleh Andrea di dalam novel SP.

(1) Personifikasi

(a) Pak Mustar dan komplotannya lekat di belakangku. Peluit melengking-lengking. Orangorang berteriak gaduh. ${ }^{20}$

(b) Klakson sepeda motor dan kliningan sepeda sahut menyahut dengan jerit mesinmesin parut dan ketukan palu para tukang sol sepatu. ${ }^{21}$
(2) Metafora

Andrea sengaja memanfaatkan pilihan kata metaforis dalam $S P$ untuk tujuan tertentu. Salah satu tujuannya adalah untuk menghidupkan deskripsi cerita. Sebagaimana yang terdapat pada data berikut.

(a) Tatapanku berkilat mengancam Arai. Ingin sekali aku membenamkan kepalanya ke mulut ikan hiu gergaji raksasa yang menganga di depanku. Itu penyiksaan karena berarti aku harus bersentuhan langsung dengan balok es di dasar peti dan menanggung beban tubuh Jimbron sendiri tak kurang dari 75 kilo, (SP, 2012:10).

(b) "Film tak pakai otak! Akting tak tahu malu! Tak ada mutunya sama sekali. Lihatlah posternya itu! Aurat diumbar ke manamana. Film seperti ini akan merusak jiwamu. Pakai waktumu untuk belajar! ${ }^{22}$

(3) Simile

Majas simile juga sering digunakan di dalam novel SP. Sebagamaina yang terdapat pada data-data berikut..

(a) Arai menyeringai seperti jin kurang sajen. ${ }^{23}$

(b) Setiap pagi kami selalu seperti semut kebakaran. Menjelang pukul tujuh, dengan membersihkan diri seadanyakarena itu, kami selalu berbau

\footnotetext{
${ }^{20}$ Andrea, Sang Pemimpi, 9.

${ }^{21}$ Andrea, 14.
}

${ }^{22}$ Andrea, 86. 
seperti ikan pari- kami tergopoh-gopoh ke sekolah. ${ }^{24}$

(4) Hiperbola

Andrea sering menggunakan majas hiperbola dalam mendeskripsikan ceritanya. Sebagaimana yang terdapat pada data-data berikut.

(a) Lalu, suatu pagi buta, sebelum shalat subuh, kelelahan setelah pontang-panting memikul ikan. $^{25}$

(b) Kami memutar otak dengan keras. Arai punya rencana gila. ${ }^{26}$

(5) Metonimia

Majas metonimia pada novel $S P$ juga dideskripsikan dengan baik oleh Andrea. Sebagaimana terdapat pada data berikut.

(a) Saat itu aku dan Jimbron sedang duduk penuh gaya di atas sepeda jengkinya yang butut. Sekelompok siswi kelas satu yang juga terlambat, nongkrong berderet-deret. Hanya aku dan Jimbron pejantan di sana. ${ }^{27}$

(b) Tapi, semuanya mereka muat sendiri ke atas tongkang untuk menggendutkan para cukong di Jakarta dan pejabat yang kongkalikong. Menjadi pendulang, nelayan jermal, dan kuli pasir, berarti mengucapkan selamat tinggal pada Tut Wuri Handayani. ${ }^{28}$

\section{Representasi Pendidikan Pada Novel Negeri 5 Menara Karya Ahmad Fuadi dan Novel Sang Pemimpi Karya Andrea Hirata}

Pengungkapan representasi pendidikan pondok pesantren dalam novel $N 5 M$ dan representasi pendidikan sekolah umum dalam novel $S P$ akan dilakukan dengan menggunakan teori representasi, teori hegemoni, dan relasi kuasa.

Selain itu, untuk mengungkap makna secara inferensial, diperlukan pemahaman yang bersifat probabilistik dan spekulatif, yang semuanya itu tergantung pada keluasan dan kedalaman pengetahuan, pandangan, dan wawasan peneliti tang berperan sebagai pembaca. ${ }^{29}$

1) Representasi pendidikan pondok pesantren pada novel N5M karya Fuadi

Berikut adalah data-data representasi pendidikan pondok pesantren yang terdapat pada novel $N 5 M$ karya Fuadi.

Saking seringnya kami berkumpul di kaki menara, kawan-kawan lain menggelari kami dengan Sahibul Menara, orang yang punya menara. ${ }^{30}$

"Jadi pilihlah suasana hati kalian, dalam situasi paling kacau sekalipun. Karena kalianlah master dan penguasa hati kalian. ${ }^{31}$

Kami sedang gila memperkaya kosakata. Lambat laun, dengan

\footnotetext{
${ }^{29}$ Sutopo, Metode Penelitian Kualitatif, Dasar Teori Dan Terapannya Dalam Penelitian.

${ }^{30}$ Fuadi, Negeri 5 Menara, 94.

${ }^{31}$ Fuadi, 108.
}

\footnotetext{
${ }^{24}$ Andrea, 58

${ }^{25}$ Andrea, 90.

${ }^{26}$ Andrea, 93.

27 Andrea, 5.

${ }^{28}$ Andrea, 56.
} 
cara ini, kami mulai bisa berbicara Arab dan Inggris sepotong-sepotong. 32

Kata mutiara sederhana tapi kuat. Yang menjadi kompas kehidupan kami kelak. 33

Man jadda wajada: sepotong kata asing ini bak mantera ajaib yang ampuh bekerja. ${ }^{34}$

Pada data tersebut mengungkap makna bahwa kata-kata pada novel N5M yang terinspirasi dari lingkungan pondok pesantren Madani (Ponpes Gontor Ponorogo) yang terkenal dengan kedisiplinannya. Santri dalam berkomunikasi sehari-hari diwajibkan menggunakan bahasa Inggris dan bahasa Arab. Jika melakukan kesalahan maka akan dikenai sanksi dan ditindak tegas. Perjuangan para santri yang menuntut ilmu di pondok pesantren tersebut benarbenar digembleng dan sangat berat bagi mereka yang baru mengawali. Akan tetapi dengan tekad yang sungguh-sungguh semata-mata karena Allah SWT akhirnya membuat santri-santri tersebut mampu melalui dan melewati dengan suka cita. Terlebih kata-kata ajaib yang kerapkali mereka gunakan yaitu Man jadda wajada sepotong kata asing "mantra" ajaib yang ampuh bekerja, kata-kata itu benar-benar memberi semangat dan sinergi positif dalam kehidupan para santri.

2) Representasi pendidikan sekolah umum pada novel $S P$ karya Andrea Berikut adalah data-data representasi pendidikan SMA yang

\footnotetext{
${ }^{32}$ Fuadi, 135.

${ }^{33}$ Fuadi, 41.

${ }^{34}$ Fuadi, 40.
}

terdapat pada novel $S P$ karya Andrea.

Ini adalah pembunuhan karakter paling sadis yang pernah kusaksikan. ${ }^{35}$

"Film tak pakai otak! Akting tak tahu malu! Tak ada mutunya sama sekali. Lihatlah posternya itu! Aurat diumbar ke manamana. Film seperti ini akan merusak jiwamu. Pakai waktumu untuk belajar! 36

Tapi, semuanya mereka muat sendiri ke atas tongkang untuk menggendutkan para cukong di Jakarta dan pejabat yang kongkalikong. Menjadi pendulang, nelayan jermal, dan kuli pasir, berarti mengucapkan selamat tinggal pada Tut Wuri Handayani. ${ }^{37}$

Pada data tersebut mengungkap makna bahwa kata pada novel $S P$ yang terinspirasi dari lingkungan masyarakat Belitung bagian timur yang pada saat itu banyak yang tidak dapat melanjutkan sekolah karena terkait dengan masalah biaya. Kata "Tut Wuri Handayani" untuk mengungkapkan "menuntut ilmu di bangku sekolah". Banyak anak-anak yang ingin melanjutkan sekolah akan tetapi harus membantu orangtua untuk mencari nafkah, akhirnya anak-anak tersebut bekerja serabutan, meskipun Belitung ada pertambangan timah, namun hal tersebut tidak dapat mengubah kesejahteraan masyarakat Belitung justru sebaliknya

\footnotetext{
${ }^{35}$ Andrea, Sang Pemimpi, 199.

${ }^{36}$ Andrea, 86.

${ }^{37}$ Andrea, 56.
} 
para cukong berduit dari kota Jakarta semakin sejahtera dengan memanipulasi dan mengeksploitasi warga setempat dengan mempekerjakannya bahkan di bawah umur, sedangkan masyarakat Belitung tetap pada kondisi memprihatinkan.

Novel ini dapat dijadikan motivasi bagi pembacanya bahwa dalam meraih cita-cita tidak harus dari tingkat ekonomi tinggi. Berbekal semangat, kemauan dan mimpi cita-cita juga dapat terwujud. Hal inilah yang menjadi keistimewaan novel $S P$, pembaca akan memperoleh pesan cerita yang menarik untuk mendorong pelajar supaya tidak menyerah dalam meraih cita-cita. Arai, Ikal, dan Jimbron yang merupakan tokoh utama dalam novel $S P$ yang berasal dari keluarga tidak mampu tetap memiliki semangat untuk bersekolah di SMA pertama yang berdiri di Belitung bagian timur. Mereka bertiga bersekolah di pagi hari dan bekerja sebagai kuli ngambat di pelabuhan ikan dini hari. Semua itu dilakukan demi meraih mimpi dan cita-cita. Arai dan Ikal melanjutkan kuliah di Jakarta, namun perjalanan mereka menuju Jakarta justru membuat mereka berpisah dan dipertemukan kembali setelah empat tahun lamanya tidak bertemu dalam sebuah tes seleksi beasiswa pendidikan S2 Sorbonne, Prancis. Kepintaran dan proposal mereka berdua akhirnya membuat Arai dan Ikal berhasil dan mendapatkan kesempatan untuk melanjutkan kuliah di Prancis. Hidup mandiri terpisah dari orang tua dengan latar belakang kondisi ekonomi yang terbatas namun punya cita-cita besar, sebuah cita-cita yang dapat terlihat dari latar belakang kehidupan mereka.

\section{KESIMPULAN}

Berdasarkan hasil dan pembahasan dapat disimpulkan: (1) terdapat pilihan kata dan leksikon kata sapaan pada novel N5M karya Fuadi dan novel SP karya Andrea, (2) terdapat leksikon bahasa daerah dalam novel $N 5 M$ karya Fuadi dan novel SP karya Andrea, (3) terdapat leksikon bahasa asing dalam novel N5M karya Ahmad Fuadi dan novel SP karya Andrea, (4) terdapat jenis-jenis majas di dalam novel $N 5 M$ karya Fuadi dan novel $S P$ karya Andrea yang difokuskan hanya pada majas personifikasi, metafora, simile, hiperbola dan metonimia. Pemanfaatan lima majas tersebut sangat produktif walaupun sebetulnya juga ada pemanfaatan jenis majas lain dengan jumlah yang cukup banyak, terdapatnya perbedaan dan kesamaan yang terkait dalam mengungkap wacana yang tersirat dengan menggunakan pengembangan teori representasi pendidikan pondok pesantren pada novel N5M karya Fuadi dan sekolah umum pada novel SP karya Andrea.

Saran yang diberikan adalah (1) bagi penelitian berikutnya, dengan diperolehnya hasil kajian stilistika deskripsi dan genetik dalam novel Negeri 5 Menara karya Ahmad Fuadi dan Sang Pemimpi karya Andrea Hirata, perlu diadakan penelitian lebih lanjut terhadap novel-novel tersebut dengan menggunakan pendekatan dan metode yang berbeda, misalnya novel $N 5 M$ karya Fuadi dan $S P$ karya Andrea dikaji dengan menggunakan metode estetika yang 
ditekankan pada aktivitas pembaca sebagai penikmat dan memberikan tanggapan terhadap karya sastra tersebut, hal tersebut bertujuan agar penelitian selanjutnya lebih bervariasi.

\section{DAFTAR PUSTAKA}

Andrea, Hirata. Sang Pemimpi. Yogyakarta: Bentang Pustaka, 2012.

Baldick, C. The Concise Oxford Dictionary of Literary Terms. Oxford: Oxford Paperback Reference, 1996.

Bungin, Burhan. Penelitian Kualitatif. Jakarta: Pranada Media, 2014.

Fuadi, Ahmad. Negeri 5 Menara. Jakarta: Gramedia, 2017.

Keraf, Gorys. Diksi Dan Gaya Bahasa. Jakarta: Gramedia, 2005.

Mudawam, Syafaul. "Asy-Syir'ah SYARI'AH-FIQIH-HUKUM ISLAM Studi Tentang Konstruksi Pemikiran Kontemporer." Jurnal Ilmu Syari'ah Dan Hukum. Vol. 46, 2012.

Nurgiyantoro, Burhan. Stilistika. Yogyakarta: Gadjah Mada University Press, 2014.

Ratna, Nyoman Kutha. Stilistika Kajian Puitika Sastra, Dan Budaya. Yogyakarta: Pustaka Pelajar, 2014.

Sutopo, HB. Metode Penelitian Kualitatif, Dasar Teori Dan Terapannya Dalam Penelitian. Surakarta: Sebelas Maret University Press, 2002. 
190| 